\title{
Chronology of desert margin in western India using improved luminescence dating protocols
}

\author{
Naveen Chauhan ${ }^{1, *}$ and P Morthekai ${ }^{1,2,3}$ \\ ${ }^{1}$ AMOPH, Physical Research Laboratory, Navrangpura, Ahmedabad 380 009, India. \\ ${ }^{2}$ Institute of Seismological Research, Raisan, Gandhinagar 382 009, India. \\ ${ }^{3}$ Birbal Sahni Institute of Palaeosciences, 53 University Road, Lucknow 226 007, India. \\ *Corresponding author. e-mail: nuc.nav@gmail.com
}

MS received 6 January 2017; revised 19 April 2017; accepted 23 May 2017; published online 23 November 2017

The present study provides improved chronology for the desert margin fluvial sediments of semi-arid region located in the Mahi river basin, western India. The sequence has preserved a near-continuous record of climate change since the Last Interglacial. An earlier attempt of dating based on feldspar IRSL chronology shows a combined effect of anomalous fading and unbleached components resulting in age inversions. The present work tries to explore the possibility of using blue light stimulated luminescence (BLSL) of quartz, infra-red stimulated luminescence (IRSL) of feldspar and the newly developed methodologies, like natural correction factor based single aliquot regeneration (NCF-SAR) protocol and decision making schemes based on distribution of doses and beta heterogeneity concept for luminescence dating of sediments. Observations suggest that quartz suffered from significant sensitivity changes during natural signal measurement and partial bleaching. A combination of NCF-SAR protocol and sample specific equivalent dose computation helped in arriving at better age estimate for present samples. The study also compares the criteria for the selection of different age models that are used at present. The age of the alluvial sequence is now bracketed between $10 \mathrm{ka}$ (upper aeolian unit) and $75 \mathrm{ka}$ (lowermost fluvial unit).

Keywords. Quartz; feldspar; luminescence; dose distribution; NCF-SAR; beta heterogeneity; India.

\section{Introduction}

Over the years, luminescence dating is extensively used to establish the chronology of the Quaternary sediments to understand the regional and global climate variability. The desert margin sediments respond sensitively to minor changes in the temperature-precipitation and are considered as potential sedimentary archives for reconstructing past climate variability. Mahi river basin is known to have preserved the sedimentary record spanning >100 ka, thus considered as one of the longest continental records of climate variability in the western India. In order to use the alluvial succession for regional and global climatic correlation (marine and continental), it is pertinent to have the reliable chronometric ages. In the absence of numerical chronology, the initial study (Pant and Chamyal 1990) estimated the age of the sedimentary succession indirectly by correlating it with the Marine Isotopic Stage-6. Following this, the first chronology of this record was based on multiple aliquot additive (MAAD) method using IRSL feldspar (samples: TL-6, 7, 8, 9, 10, 11) and the 
Australian slide method (sample: TL-6) employed on the quartz extract by Juyal et al. (2000). Thus based on these techniques, the oldest age obtained on one of the fluvial gravel bed which is about $\sim 25 \mathrm{~m}$ from top was $74 \pm 24 \mathrm{ka}$, the lower horizon of the youngest over bank sediment showed an age of $45 \pm 7 \mathrm{ka}$ and the upper horizon was dated $40 \pm 10 \mathrm{ka}$. In between, two samples showed ages of $50 \pm 6 \mathrm{ka}$ and $31 \pm 6 \mathrm{ka}$ (figure 5, Juyal et al. 2000). However, due to the turbulent water conditions and attenuation of light as a function of depth in case of fluvial sediments, it is likely that sediments may suffer from different degree of bleaching of the geological signal (inheritance). As can be seen, the above ages not only have an inherent large uncertainty but also suffer from age inversions. The plausible reasons for large uncertainty and age inversions could be (i) the shortcoming of multigrain methods (in present case MAAD) as they average over all the grains (bleached or unbleached) and (ii) anomalous fading problem associated with feldspar. A combined effect can lead to either age overestimation, if the contribution of unbleached grains is greater or age underestimation, if the anomalous fading dominates.

In view of this, the present work uses quartz extracts for measurement. The luminescence signal of quartz is fast to bleach and is unaffected by anomalous fading (Aitken 1985, 1998), so as to provide better age estimates. In addition to this, ages were also estimated using infrared stimulated luminescence (IRSL measured at $50^{\circ} \mathrm{C}$ ) of feldspar extracts to compare with quartz. A systematic measurement and dose estimation strategy was adopted. In this, the sensitivity changes during measurement were tracked and corrected via natural correction factor based single aliquot regeneration (NCF-SAR) protocol (Singhvi et al. 2011; Chauhan 2014; Chauhan et al. 2015). For estimation of ages, the distribution in equivalent doses $\left(D_{\mathrm{e}}\right)$ was analyzed using existing graphical, statistical and beta heterogeneity based models.

\section{Geological setting and sampling}

The Mahi river is the third largest river in Gujarat, India (figure $1 \mathrm{a}-\mathrm{c}$ ). It originates from $556 \mathrm{~m}$ elevation in Malwa region of Madhya Pradesh and flows about $180 \mathrm{~km}$ in Gujarat before emptying into the Gulf of Cambay. The river drains through three broad geomorphic zones, these are the upper pre-Cambrian rocky terrain comprising
Vindhyan and Aravalli ranges, the middle Quaternary alluvial plain and the lower estuarine zone (Middle-Holocene). Varying thickness (10-40 m) of Quaternary sediments that are exposed along its course indicate that sedimentation in the Mahi basin was strongly influenced by tectonics, climate and sea level changes (Pant and Chamyal 1990; Juyal et al. 2000).

Samples were collected from a $25 \mathrm{~m}$ thick sediment sequence exposed near Rayka village on the eastern bank of Mahi river (figure $1,22^{\circ} 26.937 \mathrm{~N}$, $\left.73^{\circ} 05.259 \mathrm{E}\right)$. Figure $1(\mathrm{~d})$ gives the generalized stratigraphy of the Rayka section. From bottom upwards the succession begins with $3 \mathrm{~m}$ thick marine clay which is overlain by $4-5 \mathrm{~m}$ thick planar cross-stratified gravel (Gravel-1). This is overlain by $\sim 5 \mathrm{~m}$ thick sand-silt and carbonate layers. Overlying this, is $3.5 \mathrm{~m}$ thick gravel (Gravel2) containing infrequent laminated sand layers. The fluvial succession ends with the deposition of 5-10 $\mathrm{m}$ thick medium to fine sand and silt containing three distinct weathered horizons (flood plain palaeosols). Finally, the aeolian sand sheet marks the termination of sedimentation at Rayka (Juyal et al. 2000 and reference therein).

In order to maintain consistency in the sampling, six fresh samples were collected from the same stratigraphic horizons as carried out by Juyal et al. (2000). Considering that the red soil in Rayka has been used as a stratigraphic marker in the north-central alluvial plain of Gujarat (Juyal et al. 2000), two samples, viz., Sample RYK-V-3(III) and RYK-V-3(III)A, were collected from this horizon (figure 1) in order to constrain the timing of the red soil sediment deposition. RYK-V-3(III) was from red soil layer, while RYK-V-3(III)A was collected from a sandy soil lying $1 \mathrm{~m}$ below the red soil layer. Except for sample, RYK-V-2(II) which was collected as a sediment block wrapped in aluminum foil and black cloth, all other samples were collected in light tight steel tubes having a sealed bottom and a tight fitting cap with a rubber ' $\mathrm{O}$ ' ring inside to prevent light exposure of samples.

\section{Sample preparation}

In order to extract quartz, samples were sequentially treated with $1 \mathrm{~N} \mathrm{HCl}$ to remove the carbonates, $40 \% \mathrm{H}_{2} \mathrm{O}_{2}$ to remove the organic matter followed by $90-150 \mu \mathrm{m}$ grain size separation by sieving. The sieved samples were treated with $40 \%$ $\mathrm{HF}$ acid for $80 \mathrm{~min}$ to remove outer $\sim 20 \mu \mathrm{m}$ alpha 

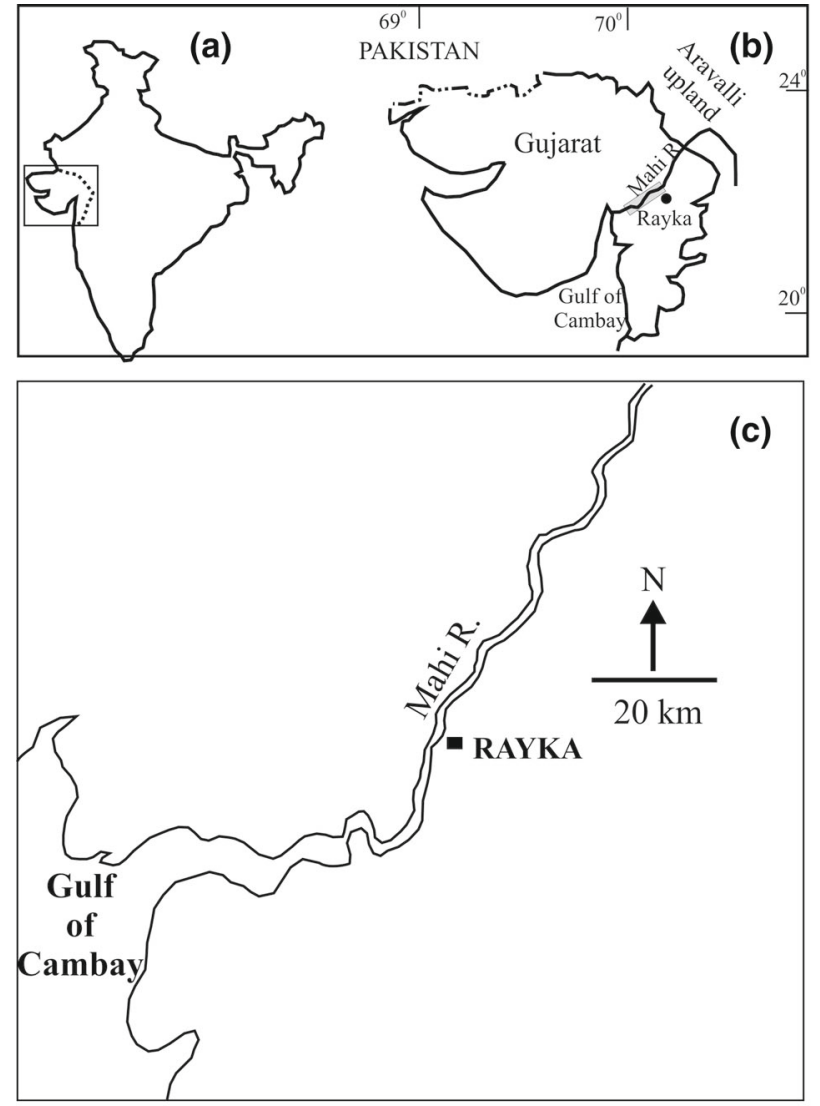
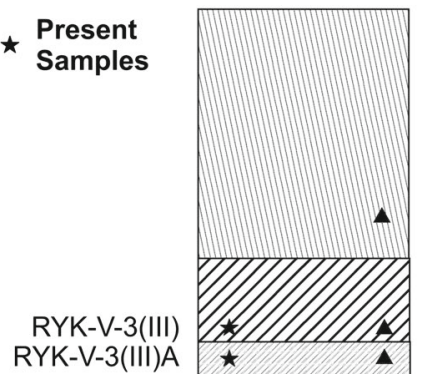

$\Delta$

RYK-V-3(III)A

RYK-V-2(II)

RYK-V-T
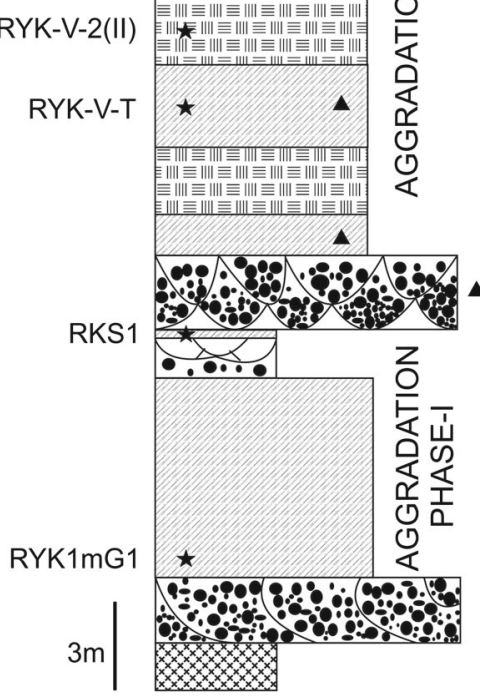

Juyal et. al. 2000

Samples

(d)

Aeolian Sand (10 $\pm 3 \mathrm{ka})$

Red Soil (40 $\pm 10 \mathrm{ka})$

Sandy Silt (31 $\pm 6 \mathrm{ka})$

Brown Soil-2

Sandy Silt $(50 \pm 6 \mathrm{ka})$

Brown Soil-1

Sandy Silt $(45 \pm 7 \mathrm{ka})$

Gravel-2 (65(82) $\pm 7(24)$ ka)

Sand lens

Vertisol

Sandy Silt

Gravel-1

Basal Marine Clay

Figure 1. ( $\mathbf{a}, \mathbf{b}$ and $\mathbf{c})$ Location of the Rayka section in the India. (d) Stratigraphy of Rayka site and description of present samples and samples analyzed by Juyal et al. (2000). Juyal et al. (2000) gave oldest age (74 \pm 24 ka) for the sample of Gravel-2, after taking mean of feldspar age $(65 \pm 18 \mathrm{ka})$ and quartz age $(82 \pm 24 \mathrm{ka})$.

skin of quartz. Following this, pure quartz was extracted by applying a magnetic field of $\sim 10,000$ Gauss in a Frantz magnetic separator (Model LB1). The extracted quartz was checked for feldspar contamination by stimulating it with infrared diodes mounted in Ris $\varnothing$ TL/OSL reader. Three out of six samples (RYK-V-T, RKS1, RYK1mG1) showed significant IRSL signal for a known dose indicating presence of feldspar in the quartz extract. The feldspar was probably present as inclusion as IRSL/BLSL ratios did not improve even after repeated treatments with HF. Figure 2(a) shows the OSL decay curve for the sample RYK-V-3(III), the inset shows the signal corresponding to infrared stimulation.

For feldspar dating, K-feldspar grains were extracted from 150-210 $\mu \mathrm{m}$ fraction using heavy liquid (sodium poly-tungstate) of density $2.58 \mathrm{~g} . \mathrm{cm}^{-3}$. The alpha dose contribution in the outer $\sim 20 \mu \mathrm{m}$ layer of the grains was removed by etching with $10 \% \mathrm{HF}$ acid for 40 min followed by 30 min treatment with $12 \mathrm{~N} \mathrm{HCl}$ to remove fluorides.

\section{Measurements}

\subsection{Equivalent dose determination}

All the luminescence measurements were done in an automated Ris $\varnothing$ TL/OSL reader model DA20 (Thomsen et al. 2006). For samples having feldspar inclusions, the luminescence contribution of feldspar was removed by using IR stimulation $\left(870 \pm 40 \mathrm{~nm}, 50^{\circ} \mathrm{C}, 100 \mathrm{~s}\right)$, prior to each blue light stimulated luminescence (BLSL) readout (Jain and Singhvi 2001). The samples were stimulated using blue diodes $(470 \pm 20 \mathrm{~nm})$ and the emission was detected in UV window using band pass filter (7 mm Hoya U-340 filter). The preheat temperature for the samples was ascertained by dose recovery preheat plateau test, in which the sample RYK-V2(II) was first bleached with blue light at room temperature for $100 \mathrm{~s}$ and given a known dose of 45 Gy which was recovered using variable preheat temperature. The pre-heating time was kept constant at $10 \mathrm{~s}$ and the dose ratio (recovered 


\section{RYK-V-3(III)}
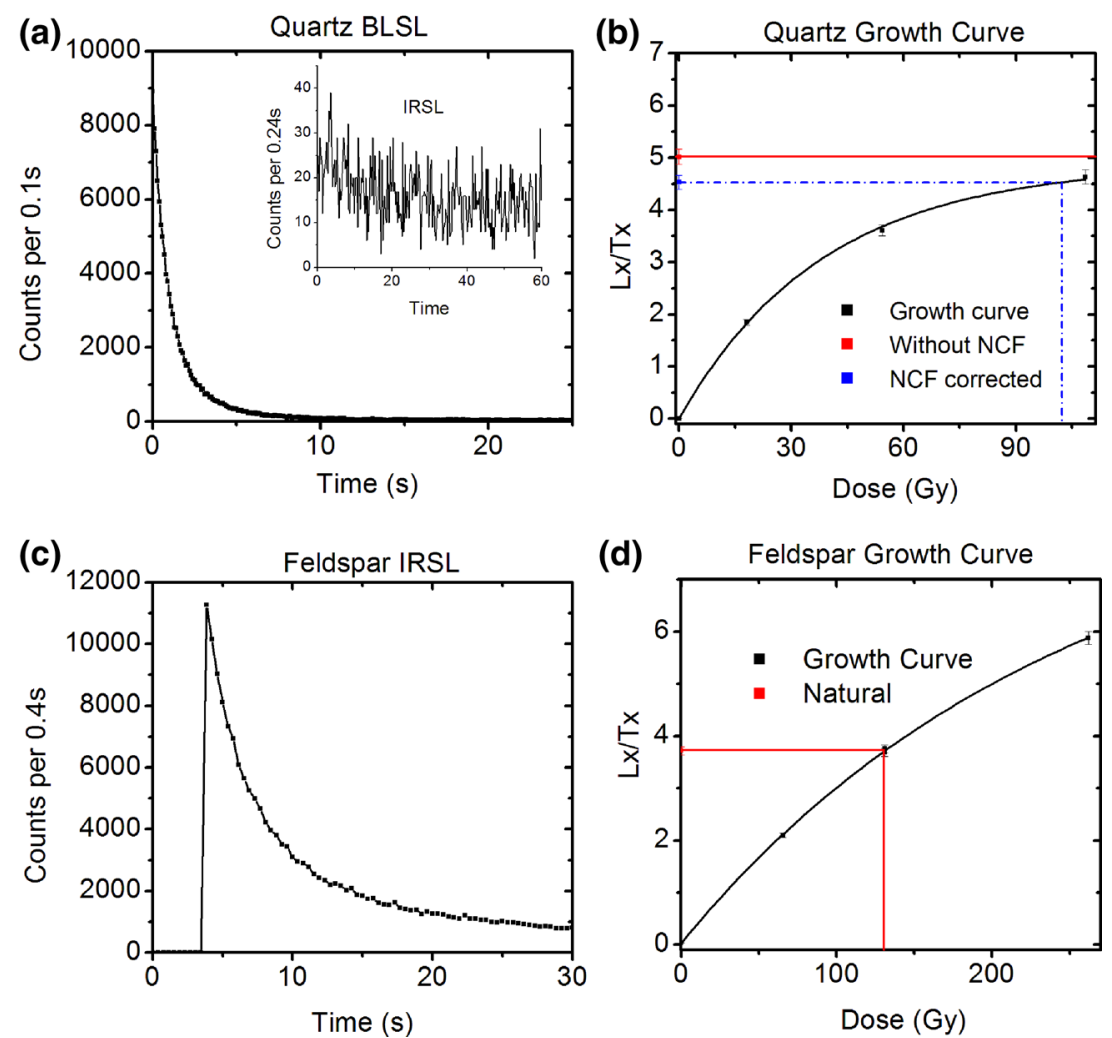

Figure 2. Measurement results for one of the samples (RYK-V-3(III)). (a) OSL decay curve and IRSL test result (inset) of quartz samples. (b) Growth curve obtained for quartz along with natural signal $\left(L_{n} / T_{n}\right)$ and the NCF corrected $\left(L_{n} / T_{n}\right)$ signal (dashed line). (c) IRSL decay curve for one of the feldspar samples. (d) Growth curve shown for feldspar sample.

dose/given dose) was measured at temperatures varying from 180 to $280^{\circ} \mathrm{C}$. It was observed that a stable dose ratio lies between 220 and $280^{\circ} \mathrm{C}$. Thus we opted for a preheat temperature of $240^{\circ} \mathrm{C}$ for $10 \mathrm{~s}$ for all the measurements. The samples were was measured using SAR protocol for palaeodose estimation (Murray and Wintle 2000). All the samples fulfilled the criteria required for SAR protocol such as insignificant recuperation signal and recycling ratio lying within $10 \%$ of unity. However, it was observed that the test dose normalized natural signal $\left(L_{n} / T_{n}\right)$ was always well above the regenerated growth curve even after giving increased regeneration doses (figure $2 \mathrm{~b}$ ). This was one of the reasons that earlier workers could not use quartz for age estimation. Singhvi et al. (2011) suggested that such behaviour of quartz could be due to the change in sensitivity during measurements of the natural signal such that the natural and test dose luminescence signals are recorded at different sensitivities. In order to overcome this, natural correction factor (NCF) based SAR (NCFSAR) protocol (Singhvi et al. 2011; Chauhan et al. 2015) was adopted. Table 1 provides simplified
NCF-SAR protocol steps. Using the ratio of the intensity of the two $110^{\circ} \mathrm{C}$ TL peaks (before and after natural OSL measurements [TLstep $2,110^{\circ} \mathrm{C}$, $0 \mathrm{~s}] /\left[\right.$ TLstep $\left.7,110^{\circ} \mathrm{C}\right]$ ) for same test dose (TD), which is termed as the Natural Correction Factor (NCF), the change in the natural $L_{n} / T_{n}$ was quantified and corrected.

In principle, if there is no sensitivity change during the natural OSL measurement, the NCF ratio should be near unity. However, in the present study, all samples showed ratio $>1$ (table 2) implying a decrease in the natural OSL sensitivity. The NCF ratio ranged from 1.04 to 1.39 . The natural luminescence signal $\left(L_{n} / T_{n}\right)$ was corrected using equation (1) (Singhvi et al. 2011) and the NCF corrected value $\left(L_{n} / T_{n}\right)_{\text {corrected }}$ is interpolated on to the regeneration growth curve (figure $2 \mathrm{~b}$ ).

$$
\left(\frac{L_{n}}{T_{n}}\right)_{\text {corrected }}=\left(\frac{L_{n}}{T_{n}}\right) \times \frac{1}{N C F} .
$$

The equivalent beta dose $\left(D_{e}\right)$ is computed by subtracting the test dose given before the natural signal measurements (i.e., in step 1, table 1). 
Table 1. Steps of NCF-SAR Protocol used for measurements.

\begin{aligned} \hline Steps & \multicolumn{1}{c}{ Treatment } \\ \hline 1 & Natural sample + test dose (TD) \\ 2 & TL $\left(200^{\circ} \mathrm{C}, 0 \mathrm{~s}\right) \\ 3 &$ Preheat $\left(240^{\circ} \mathrm{C}, 10 \mathrm{~s}\right) \\ 4 &$ OSL (Blue diodes, $70 \%$ power, $\left.125^{\circ} \mathrm{C}, 40 \mathrm{~s}\right)^{*} \\ 5 &$ TL $\left(200^{\circ} \mathrm{C}, 0 \mathrm{~s}\right) \\ 6 &$ TD \\ 7 & TL $\left(200^{\circ} \mathrm{C}, 0 \mathrm{~s}\right) \\ 8 &$ OSL (Blue diodes, $70 \%$ power, $\left.125^{\circ} \mathrm{C}, 40 \mathrm{~s}\right)^{*} \\ 9 &$ Bleach (Blue diodes, $\left.70 \%, 200^{\circ} \mathrm{C}, 100 \mathrm{~s}\right) \\ 10 &$ Regeneration dose $(\mathrm{R} 1, \mathrm{R} 2, \mathrm{R} 3,0, \mathrm{R} 1) \\ 11 &$ Preheat $\left(240^{\circ} \mathrm{C}, 10 \mathrm{~s}\right) \\ 12 &$ OSL (Blue diodes, $70 \%$ power, $\left.125^{\circ} \mathrm{C}, 40 \mathrm{~s}\right)^{*} \\ 13 &$ TD \\ 14 & TL $\left(200^{\circ} \mathrm{C}, 0 \mathrm{~s}\right) \\ 15 &$ OSL (Blue diodes, $70 \%$ power, $\left.125^{\circ} \mathrm{C}, 40 \mathrm{~s}\right)^{*} \\ 16 &$ Repeat from step 9\end{aligned}

*IRSl cleaning was performed in samples having significant feldspar contamination.

The table gives the measurement steps for NCF-SAR protocol. The ratio of $110^{\circ} \mathrm{C}$ TL peaks in step 2 and step 7 are used for correcting sensitivity changes occurring during first preheat and natural OSL signal measurement of sample.

For feldspar dating, standard SAR procedure was followed in which the preheat temperature was $250^{\circ} \mathrm{C}$ for $60 \mathrm{~s}$. The samples were stimulated at $50^{\circ} \mathrm{C}$ with IR diodes and a violet-blue luminescence emission $(395 \pm 50 \mathrm{~nm})$ was detected by PMT through the combination of optical filters Corning 7-59 (4 mm) and BG-39 (2 mm).

\subsection{Dose rate estimations}

For dose rate estimations, $\mathrm{U}$ and Th concentrations were was estimated using thick source alpha pair counting technique using the $\mathrm{ZnS}(\mathrm{Ag})$ coated screen in PMT based daybreak alpha counters (Aitken 1985). The K concentration was estimated using $1.46 \mathrm{MeV}$ gamma energy peak of ${ }^{40} \mathrm{~K}$ in $\mathrm{NaI}(\mathrm{Tl})$ detector and comparing it against a known standard of $\mathrm{KCl}$. The contribution of cosmic rays was estimated by using the methodology suggested by Prescott and Hutton (1994). However, due to the depth of the overlying sediments, the contribution of the cosmic rays to the total dose rate is very small $(<2 \%)$. The water content which attenuates the radiation dose was estimated by averaging the water content as received with that of the saturated water content a sample can hold. $13.0 \pm 0.5 \%$ of $\mathrm{K}$ was assumed for internal dose rate calculation that is required for feldspar chronology (Zhao and $\mathrm{Li}$ 2005).

\section{Equivalent dose computation and age, estimates}

In order to estimate $D_{e}, 35$ or more aliquots (Chauhan and Singhvi 2011) of a sample were measured using the methodology discussed above and their individual $D_{e}$ were computed for quartz as well as feldspar. In case of feldspar, $D_{e}$ estimates would have suffered from anomalous fading, so fading rates (g-values; \%/decade and $\rho^{\prime}$ values; dimensionless number, Huntley 2006) were measured using SAR protocol (figure 3a, Auclair et al. 2003). Considering the depositional ages of the samples, standard fading correction procedure by Huntley and Lamothe (2001) would be inappropriate, hence, the fading in feldspar was corrected by Kars et al.'s 2008 procedure in which $\rho^{\prime}$, a dimensionless number representing the extent of

Table 2. Radioactivity concentration and age estimates for NCF-corrected quartz OSL and feldspar IRSL.

\begin{tabular}{lccccccccr}
\hline \multirow{2}{*}{ Samples } & $\begin{array}{c}\text { Max. } \\
\text { NCF }\end{array}$ & $\begin{array}{c}\mathrm{U} \\
(\mathrm{ppm})\end{array}$ & $\begin{array}{c}\mathrm{Th} \\
(\mathrm{ppm})\end{array}$ & $\mathrm{K} \%$ & $\begin{array}{c}\mathrm{DR} \\
\text { Gy/ka }\end{array}$ & $\begin{array}{c}\text { Minimum } \\
\text { age (ka) }\end{array}$ & $\begin{array}{c}\text { CAM } \\
\text { age (ka) }\end{array}$ & $\begin{array}{c}\text { Feldspar } \\
\text { age (ka) }\end{array}$ & $\begin{array}{c}\text { Juyal et al. (2000) } \\
\text { age (ka) }\end{array}$ \\
\hline RYK-V-3(III) & 1.18 & $1.3 \pm 0.3$ & $4.4 \pm 1.0$ & $1.6 \pm 0.1$ & $2.0 \pm 0.1$ & $\mathbf{2 6} \pm \mathbf{4}^{*}$ & $\mathbf{4 7} \pm \mathbf{5}^{*}$ & $60 \pm 5$ & $40 \pm 10$ \\
RYK-V-3(III)A & 1.16 & $1.5 \pm 0.2$ & $3.5 \pm 0.7$ & $1.5 \pm 0.1$ & $1.7 \pm 0.1$ & $38 \pm 6$ & $\mathbf{4 9} \pm \mathbf{4}$ & $51 \pm 6$ & $31 \pm 6$ \\
RYK-V-2(II) & 1.39 & $3.2 \pm 0.5$ & $3.1 \pm 1.7$ & $1.5 \pm 0.1$ & $2.3 \pm 0.2$ & $43 \pm 7$ & $\mathbf{5 1} \pm \mathbf{5}$ & $45 \pm 6$ & - \\
RYK-V-T & 1.37 & $2.8 \pm 0.8$ & $7.0 \pm 2.6$ & $1.7 \pm 0.1$ & $2.3 \pm 0.2$ & $47 \pm 7$ & $\mathbf{5 4} \pm \mathbf{7}$ & $50 \pm 6$ & $50 \pm 6$ \\
RKS1 & 1.23 & $3.0 \pm 0.6$ & $9.0 \pm 1.9$ & $1.1 \pm 0.1$ & $1.9 \pm 0.2$ & $59 \pm 9$ & $\mathbf{6 6} \pm \mathbf{7}$ & - & $65 \pm 18(82 \pm 24)$ \\
RYK-1mG1 & 1.39 & $2.2 \pm 0.6$ & $6.2 \pm 1.9$ & $1.5 \pm 0.1$ & $1.9 \pm 0.2$ & $54 \pm 9$ & $\mathbf{7 5} \pm \mathbf{9}$ & $51 \pm 9$ & -
\end{tabular}

*Age is between minimum $26 \pm 4$ and mean $47 \pm 5$ ka.

\# Feldspar ages of all present samples are corrected for fading and those of Juyal et al. (2000) are uncorrected.

The table gives the radioactivity concentrations of Uranium (U), Thorium (Th) and Potassium (K), the final dose rate (DR), the minimum and CAM ages estimated for quartz and gives the ages estimated for feldspar with anomalous fading correction using Kars et al. (2008). It also gives the maximum values of NCF factors obtained for different samples and compares the chronology results with published work of Juyal et al. (2000). Ages in bold numbers represent acceptable ages for the present sequence. 
Sample: RYK-V-3(III)
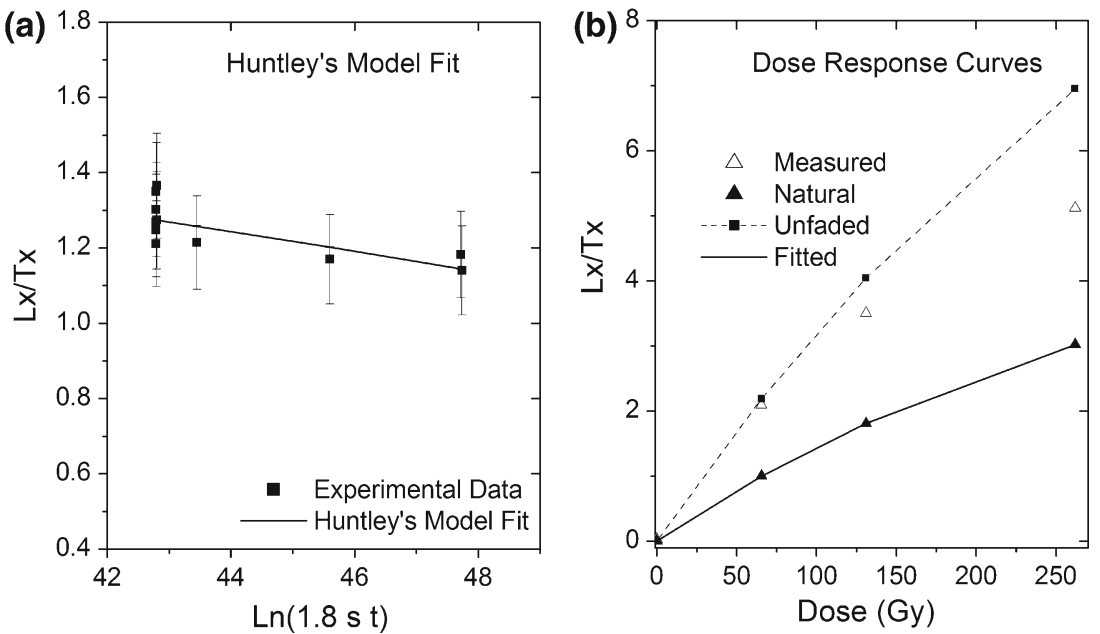

Figure 3. (a) Fading rate measurements (Auclair et al. 2003) and fitting using equation (3) of Huntley (2006). (b) Dose response curves (DRC) of sample RYK-V-3(III) that were used for fading correction as per Kars et al. (2008). Measured: Measured DRC in the laboratory. Unfaded: DRC that was corrected for laboratory fading. Natural: Corrected DRC for given laboratory doses, but at the natural dose rate.

fading, can be estimated from the fading rate measurements (figure 3a). The dose response curve measured in the laboratory was corrected for the fading to obtain the actual dose response curve during the burial period as shown in figure 3(b) (Kars et al. 2008; for more details about the correction procedure, please see Morthekai et al. 2011). The $L_{n} / T_{n}$ was interpolated on to the dose response curve to calculate the corrected $D_{e}$ estimates.

There was high scatter in $D_{e}$ values (both NCF-corrected quartz OSL and feldspar IRSL $D_{e}$ values) for all samples as can be seen from the histogram and the radial plots (figure $4 \mathrm{a}-\mathrm{d}$ ). High scattering can arise due to external factors, like partial bleaching, sediment mixing, fluctuation near saturation dose, bioturbation, etc., or inherent factors like beta heterogeneity. For some samples, the maximum $D_{e}$ was as high as $\sim 6$ times the minimum $D_{e}$ and thus selection of appropriate $D_{e}$ for age estimation becomes nontrivial. The $D_{e}$ estimation was done considering different existing methodologies following the steps shown in figure 5. In this methodology, the conventional method of using histogram and radial plots (Galbraith 1990) was used along with two mathematical and systematic methodologies by Bailey and Arnold (2006) and Chauhan and Singhvi (2011). The histogram and radial plots are graphical methods used to decide the bleachablity of sample using the spread of distribution and over-dispersion (OD) (table 3a, b) and suggest to use mean (i.e., central age model
$(\mathrm{CAM}))$ or minimum age (MAM)) methods. The Bailey and Arnold (2006) model decides the bleachablity based on distribution parameters as Kurtosis $(\mathrm{K})$, skewness $(\mathrm{C})$, and OD (table 3 ) and provides the appropriate age model (viz., CAM, MAM3, MAM4 or least $5 \%$ ) to be used for age computation following an algorithm. The Chauhan and Singhvi (2011) method relies upon the inherent $D_{e}$ distribution due to heterogeneity in beta dose deposited by ${ }^{40} \mathrm{~K}$. It uses the ratio of maximum to minimum ${ }^{40} \mathrm{~K}$ beta dose (RMM ratio; table $3 \mathrm{a}$ ) as an indicator of bleachability based on the fact that any distribution over and above beta heterogenieity is attributed to external factors like partial bleaching, sediment mixing or fluctuation in the interpolating points in the nearly saturating dose response curve. The RMM ratio is computed after deconvoluting the component of uniform dose (deposited by $\mathrm{U}$, Th and their daughter radionuclides) and nonuniform dose (deposited by ${ }^{40} \mathrm{~K}$ feldspar hotspots) and taking ratio of maximum and minimum nonuniform dose values, i.e., the ${ }^{40} \mathrm{~K}$ beta dose values. The detailed methodology of computation of RMM ratio is provided in Chauhan and Singhvi (2011).

Henceforth, the dose can be evaluated using suggested age models. The different age models MAM3, MAM4, CAM, and least 5\% discs, argue the use of different approaches for estimating the correct $D_{e}$ value (Galbraith and Green 1990; Galbraith and Laslett 1993; Olley et al. 1998; Roberts et al. 2000; Arnold and Roberts 2009; Arnold et al. 2009; Chauhan and Singhvi 2011). 

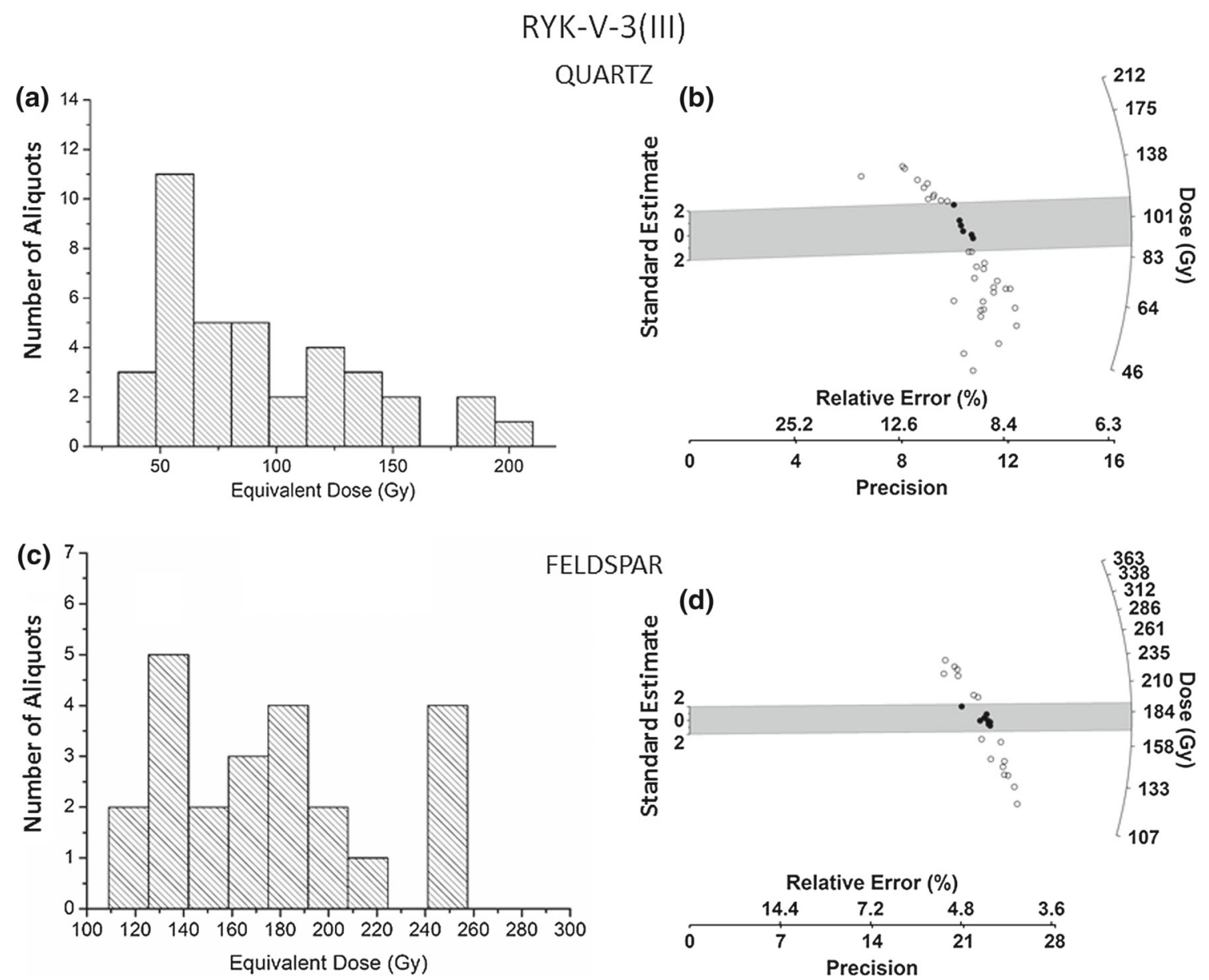

Figure 4. (a and b) Histogram and radial plot of quartz $D_{e}$ s obtained using NCF-SAR protocol for the sample RYK-V3(III). (c and d) Fading corrected $D_{e}$ histogram and radial plot estimated using feldspar for same sample.

One of the important points to be noted is that no model till now estimates the extent of bleaching (proportion of bleached and unbleached grains in distribution) and samples are considered either perfectly bleached or perfectly unbleached such that either the mean age or the minimum age is considered to be correct estimate of the dose and there is nothing in between these two limits. This is contrary to the natural environment, where sediments can be bleached to different extents. The above models do not have provision to accommodate such a condition. Particularly for dry-land sediments, which by virtue of their depositional pattern are likely to suffer from differential bleaching under same depositional environment, the identification of bleaching extent and thus estimating the correct dose on this basis becomes important.

The distribution in the radial plot and histogram (figure 4) suggest that all the samples are partially bleached and hence solicit the use of minimum age models for all the samples. Table 2 details the
MAM and CAM ages for quartz along with the fading corrected feldspar ages and published ages (Juyal et al. 2000). The ages obtained using minimum age model (table 2) are too low for some of the samples considering regional context and will also result in age reversals in the stratigraphic succession. However, use of mean ages for all the samples is also not advisable as samples from fluvial sequences can suffer from partial bleaching. Following section discusses the dose distribution in each individual sample and the variation in analysis and predictions of different age models.

The sample RYK-V-3(III) was collected from a red soil horizon which is considered to be a stratigraphic marker in alluvial plains of Gujarat. Based on the MAAD feldspar chronology, this horizon was dated to $40 \mathrm{ka}$ (Juyal et al. 2000). Since the overlying aeolian sediments were dated $10 \mathrm{ka}$ (Juyal et al. 2000) and it is unlikely that palaeosols can develop during the glacial phase, it can be hypothesized that the age of the palaeosols should be $>25$ ka. 


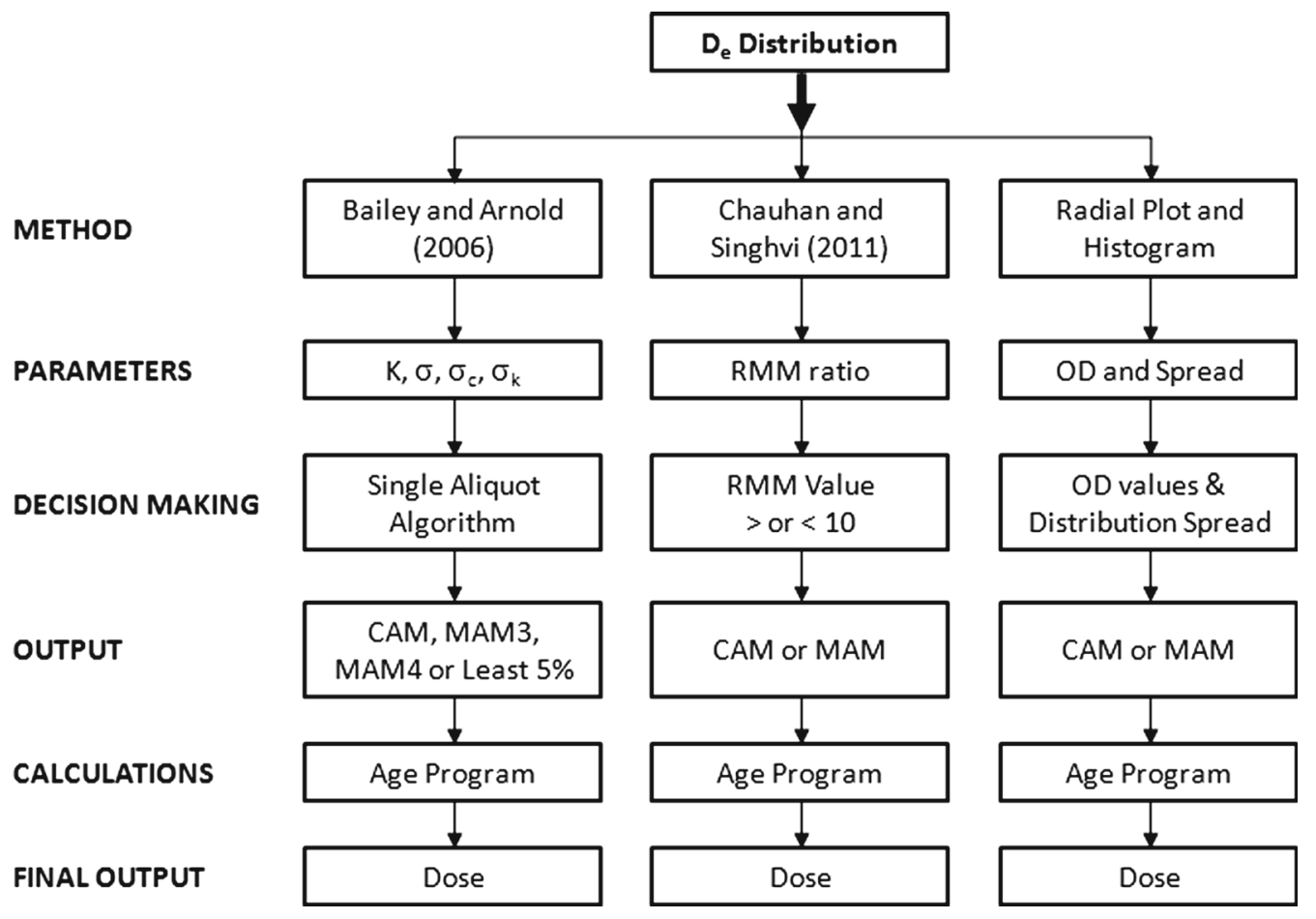

Figure 5. Steps followed for $D_{e}$ estimations using different procedures.

The decision making scheme following figure S2 (Supplementary data) of Bailey and Arnold (2006) suggest that the sample is partially bleached. The distribution of doses on radial plot and histogram shows significant scatter in the values. The scatter in dose could be due to inherent distribution and/or due to external factors as discussed earlier. The minimum age of the sample is $26 \pm 4$ ka (table 2 ). The RMM ratio calculated as per Chauhan and Singhvi (2011) gives a value of $9.8 \pm 2.5$ (table $3 \mathrm{a}$ ) which lies at threshold of the well bleached and poorly bleached (i.e., $\mathrm{RMM}=10$ ) sample. This suggests that sample is possibly not adequately bleached; however, the contribution of partial bleaching component is not very significant. Thus the mean age of sample should be considered as an upper bound and the actual age should lie between the minimum age ( $26 \pm 4 \mathrm{ka})$ and the mean age $(47 \pm 5 \mathrm{ka})$.

A significant distribution can arise solely due to heterogeneity in beta dose deposition. In case of samples having very small fraction of partially bleached sediments as is the case with the present samples, if not taken into consideration, it may lead to age underestimation.

In the present case, possibly, mean of the minimum age (26 $\pm 4 \mathrm{ka})$ and mean age $(47 \pm 5 \mathrm{ka})$, which is $37 \pm 3 \mathrm{ka}$, would be the closest approximation of the actual age of the sediment. In the foregoing, it is evident that we lack an age model which can estimate the extent of bleaching of the sample and then compute the age.

The feldspar age obtained using the CAM model as suggested by Bailey and Arnold (2006) gave an age of $60 \pm 5 \mathrm{ka}$. Beta heterogeneity model cannot be applied to feldspar because majority of feldspar grains are bright and thus do not satisfy conditions of the model. So methodology using RMM ratio to distinguish between partially bleached and well bleached samples cannot be used for feldspars.

The sample RYK-V-3(III)A was collected $\sim 1 \mathrm{~m}$ below RYK-V-3(III) from a sandy silt layer within the red soil horizon and was dated $31 \pm 6 \mathrm{ka}$ by Juyal et al. (2000). The age of this sample was stratigraphically inverted.

The MAM and CAM age of the sample are respectively $38 \pm 6$ and $49 \pm 4 \mathrm{ka}$ (table 2 ). The OD is about $29 \%$ and spread on radial plot and histogram seems quite high. However, the mathematical models, i.e., Chauhan and Singhvi (2011) (with RMM ratio of 5.6 \pm 1.4 , table 3a) and Bailey and Arnold (2006) suggested that the quartz sample is well bleached, hence the CAM age of $49 \pm 4 \mathrm{ka}$ can be used. The CAM age is also in accordance with geological settings and stratigraphy, thus CAM possibly provides best age estimate of present sample. The feldspar gave an age of $51 \pm 6 \mathrm{ka}$ using minimum age model. 
Table 3. The distribution parameters of NCF-corrected quartz OSL and feldspar IRSL $D_{e}$ values.

\begin{tabular}{lcccccc} 
(a) Quartz & OD $(\%)$ & Skewness & Kurtosis & $\boldsymbol{\sigma}_{c}$ & $\sigma_{k}$ & RMM ratio \\
\hline Sample & 44 & 0.46 & -0.22 & 0.40 & 0.79 & $9.8 \pm 2.5$ \\
RYK-V-3(III) & 29 & 0.03 & -0.74 & 0.40 & 0.79 & $5.6 \pm 1.4$ \\
RYK-V-3(III)A & 25 & 0.22 & -0.30 & 0.42 & 0.84 & $5.4 \pm 1.7$ \\
RYK-V-2(II) & 27 & 1.153 & 3.24 & 0.40 & 0.81 & $6.8 \pm 1.9$ \\
RYK-V-T & 23 & 0.82 & 0.75 & 0.43 & 0.87 & $6.6 \pm 2.7$ \\
RYKS1 & 30 & 0.75 & 2.54 & 0.44 & 0.88 & $6.9 \pm 2.0$ \\
RYK1mG1 & & & & & &
\end{tabular}

(b) Feldspar

\begin{tabular}{lcccccc} 
Sample & OD $(\%)$ & Skewness & Kurtosis & $\sigma_{c}(n *)$ & $\sigma_{k}$ & $\rho^{\prime}\left(x 10^{-6}\right)$ \\
\hline RYK-V-3(III) & 25 & 0.31 & -0.67 & $0.5(24)$ & 1 & $3.2 \pm 0.7$ \\
RYK-V-3(III)A & 35 & 0.82 & 2.54 & $0.5(24)$ & 1 & $4.4 \pm 1.7$ \\
RYK-V-2(II) & 49 & -0.12 & -3.45 & $0.52(22)$ & 1.04 & $4.0 \pm 1.2$ \\
RYK-V-T & 33 & -0.15 & -0.18 & $0.5(24)$ & 1 & $3.5 \pm 1.1$ \\
RYKS1 & NA & NA & NA & NA & NA & - \\
RYK1mG1 & 47 & 0.77 & 3.35 & $0.53(21)$ & 1.07 & $2.7 \pm 0.9$ \\
\hline
\end{tabular}

Table ( $\mathrm{a}$ and $\mathrm{b}$ ) gives the different parameters of distribution used by for quartz and feldspar respectively. Here OD refers to over-dispersion $\sigma_{c}$ and $\sigma_{k}$ to critical values of skewness and kurtosis respectively. In these tables, $\rho^{\prime}$ is a dimensionless number representing the extent of fading, RMM ratio represents ratio of maximum to minimum beta dose estimated from dose distribution.

The sample RYK-V-2(II) was collected from a gray colour pedogenised sediment horizon and was not dated by Juyal et al. (2000). The MAM and CAM age of the sample are $43 \pm 7 \mathrm{ka}$ and $51 \pm 5 \mathrm{ka}$, respectively (table 2 ). The OD value of the present sample is $25 \%$ and $\mathrm{RMM}$ value is $5.4 \pm 1.7$ (table 3a), which is least in the present sequence. Both the mathematical models suggest that the sample was well bleached before burial, hence the CAM age model is applicable. The dose distribution in feldspar show wide scatter, implying partial bleaching, MAM was used which gave an age of $45 \pm 6 \mathrm{ka}$ which result in reversal in stratigraphy. The quartz CAM age of $51 \pm 5 \mathrm{ka}$ suggested by mathematical models is in accordance to stratigraphy and thus accepted for present sample.

The sample RYK-V-T was collected from the transition zone between the pedogenised and the underlying host and dated to $50 \pm 6 \mathrm{ka}$ by Juyal et al. (2000). The fading corrected feldspar IRSL age using MAM3 also gave the same age of $50 \pm 6 \mathrm{ka}$.

The dose distribution of quartz sample gave an OD of $27 \%$. The MAM and CAM age of sample are $47 \pm 7$ and $54 \pm 7 \mathrm{ka}$, respectively (table 2 ). The model of Bailey and Arnold (2006) which spread in radial plot indicates that the sample has undergone partial bleaching, hence the MAM should be used to obtain an age estimate. The RMM ratio is only
$6.8 \pm 1.9$ (table 3a) which as per beta heterogeneity method suggest that the sample is well bleached and thus CAM age should be used. The MAM age lead to reversal in the ages of preceding samples which were validated by the mathematical models. The CAM age is stratigraphically more consistent and in accordance with beta heterogeneity concept.

The sample RKS1 was collected from the sandy horizons immediately below the gravel bed- 2 of Juyal et al. (2000). It has been suggested that the sand horizon constitute a part of the braided bar environment. The sand horizon consists of well sorted fluvial sand, hence it is expected to be well bleached. The gravel bed just above this sand lens was dated $65 \pm 18 \mathrm{ka}$ using feldspar and $82 \pm 24 \mathrm{ka}$ using Australian slide method of quartz (Juyal et al. 2000).

The sample showed the least OD value of $23 \%$ among all the samples from sequence and low RMM ratio $6.6 \pm 2.7$ (table $3 \mathrm{a}$ ). Both of these suggest sample to be well bleached. The MAM and CAM age of the sample are $59 \pm 9$ and $66 \pm 7 \mathrm{ka}$ respectively (table 2). Bailey and Arnold (2006) model suggested the use of MAM age based on statistical parameters. However, as the RMM ratio is low, beta heterogeneity concept advocates use of CAM age. As sand is well sorted and has lowest OD values along with small RMM ratio, it is expected that sample is well bleached. Stratigraphically both 
MAM and CAM ages seem to be acceptable; however, considering the geological setting, beta heterogeneity, small OD and RMM values, CAM age is preferable and acceptable.

This sample RYK1mG1 was collected $1 \mathrm{~m}$ above Gravel-1 of Juyal et al. (2000). The sample is from sandy silt lying above the bed and was not dated so far.

The distribution gave an OD value of $30 \%$ and the RMM ratio was $6.9 \pm 2.0$ (table $3 \mathrm{a}$ ). The MAM and CAM age of quartz are $54 \pm 9$ and $75 \pm 9 \mathrm{ka}$, respectively (table 2). The feldspar gave an age of $51 \pm 9 \mathrm{ka}$ using MAM model. The sample was suggested to be partially bleached by Bailey and Arnold (2006) algorithm. The MAM ages (quartz and feldspar both) are stratigraphically inconsistent and leads to the reversal in preceding ages predicted by mathematical models. The beta heterogeneity concept suggested the use of CAM as RMM ratio is low. The CAM age of $75 \pm 9 \mathrm{ka}$ is stratigraphically more consistent and also in accordance with geological settings and beta heterogeneity concept. It also goes along with the argument of Juyal et al. (2000) that the marine clay present below Gravel-1 must be deposited during last interglacial sea level highstand, i.e., during substage 5e.

It should be noted here that the suggestions of Bailey and Arnold (2006) in assessing whether the given sample is well bleached or not were so far applied only to quartz and are not tested for feldspar minerals. Feldspar ages, due to slower bleaching of signal compared to quartz during transportation, can be overestimated than that of quartz. Recently, there is a study which showed that if the degree of bleaching is high, then the spread in the $D_{e}$ tends to be less but the average $D_{e}$ is higher (Morthekai et al. 2017) due to the probable increase of the poorly bleached grains in the aliquot (sub-sample). This could be the reason with RYK-V-3(III) sample as its poor bleachedness had been manifested even in quartz fraction and hence led us to use CAM ages.

Based on the above discussion it can be suggested that computation of the ages from dryland sediment succession should require careful consideration of various bleaching and dose distribution constraints. Figure 6 gives the final proposed chronology of this important dry-land sediment succession in western India which may be treated as the refined chronology that can be used for climatic interpretation and regional correlation.

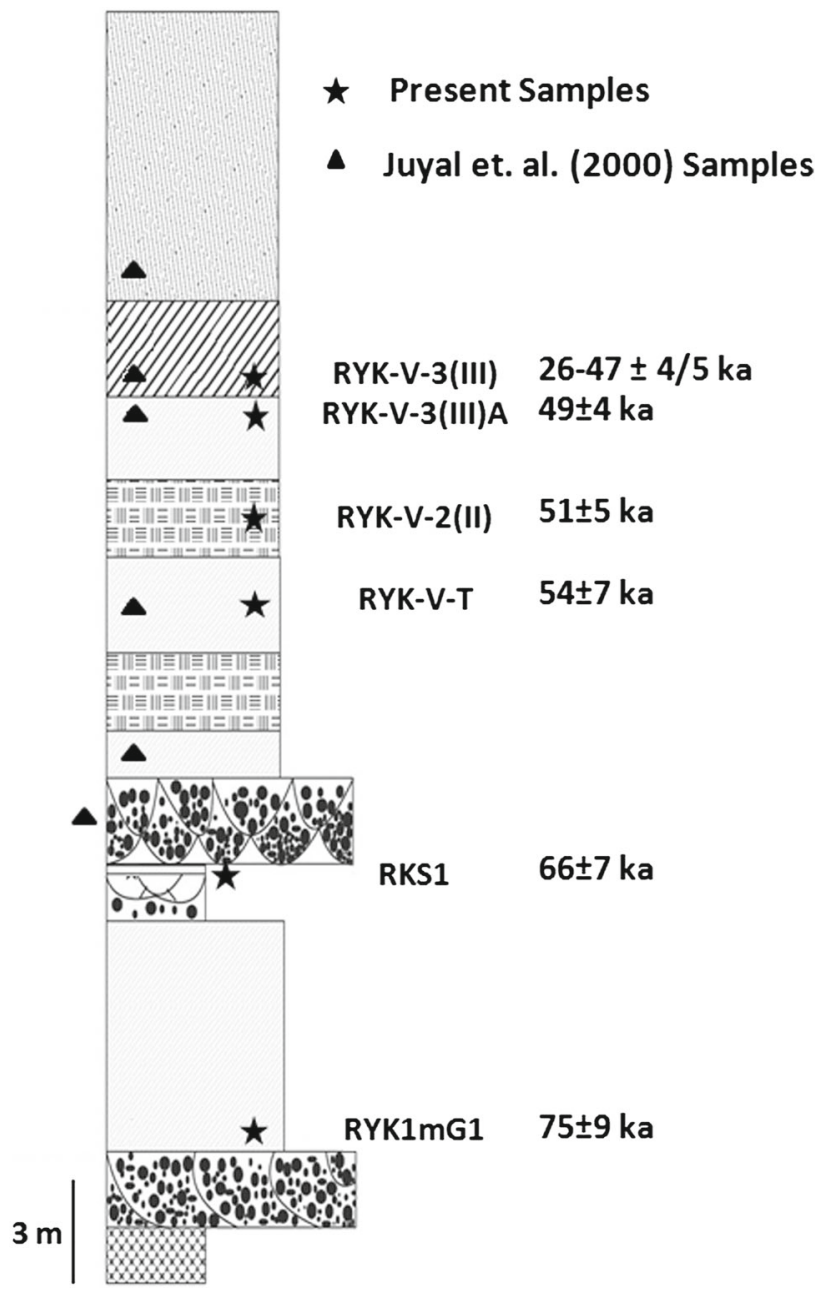

Figure 6. Final chronology of Rayka sequence.

\section{Discussion}

The nature of distribution of $D_{e}$ at Rayka sedimentary sequence in the Mahi river basin indicate different degrees of bleaching. The data obtained based on various mathematical computation suggests that both beta-heterogeneity and the variability in the bleaching of the sediments are the main causes of scatter in the $D_{e}$. This is plausible considering that stream flow pattern of the dry-land rivers tends to rise more steeply, have a sharp peak and recede more quickly, giving rise to flood events of irregular frequency and short duration. Because of this, ephemeral rivers are many times more efficient transporters of assorted sediment both as bed load and suspended load (Reid and Frostick 1997). If there is not enough time for sediment segregation, it is likely that the mineral grains may suffer from inadequate bleaching (Jain et al. 2004; Rodnight et al. 2006; Thomsen et al. 
2007; Voinchet et al. 2007; Pietsch et al. 2008). In addition to this, it is becoming increasingly evident that the sensitivity change during natural signal measurements needs to be carefully monitored; this may have a significant effect on the final age computation as observed by Singhvi et al. (2011). During analysis, it was found that the sensitivity change during natural OSL measurement can seriously affect the dose estimations. If $\mathrm{NCF}$ correction is not taken into account, then it may lead to erroneous $D_{e}$ estimation. We observed that if signal $\left(L_{n} / T_{n}\right)$ is not corrected for the natural sensitivity change, the ages can be either overestimated depending upon the age of the sediment, or the natural signal lies above the growth curve, such that no $D_{e}$ computation is possible. Further, anomalous fading should be corrected and we have used the Kars et al. (2008) corrections. Finally, the study demonstrates that heterogeneity in beta dose deposition can significantly contribute to scatter in doses and should be deconvoluted to study the effect of partial bleaching or distribution arising from other natural factors. Thus the conventional methodologies (Bailey and Arnold 2006, Radial plots and histogram analysis) used by the geochronologists should be further refined in order to account for the effect of heterogeneous beta dose deposition. Beta heterogeneity based methodology by Chauhan and Singhvi (2011) provides a limited approach to circumvent the problem associated with beta heterogeneity, but methodology is not complete and a more robust model needs to be developed to compute the ages considering the fractional contribution of partial bleached component after identification of bleaching condition. In addition to this, there is also need to develop a model for the deconvolution of bleaching and fading aspect of the feldspar.

\section{Acknowledgement}

Authors thank Prof. A K Singhvi, PRL for his continuous support and suggestions during the execution of this work.

\section{References}

Aitken M J 1985 Thermoluminescence dating; Academic Press, London.

Aitken M J 1998 An introduction to optical dating: The dating of quaternary sediments by the use of photon- stimulated luminescence; Oxford University Press, New York.
Arnold L J and Roberts R G 2009 Stochastic modelling of multi-grain equivalent dose (De) distributions: Implications for OSL dating of sediment mixtures; Quat. Geochronol. 4 204-230.

Arnold L J, Roberts R G, Galbraith R F and DeLong S B 2009 A revised burial dose estimation procedure for optical dating of young and modern-age sediments; Quat. Geochronol. 4 306-325.

Auclair M, Lamothe M and Huot S 2003 Measurement of anomalous fading for feldspar IRSL using SAR; Radiat. Meas. 37 487-492.

Bailey R M and Arnold L J 2006 Statistical modelling of single grain quartz $D_{e}$ distributions and an assessment of procedures for estimating burial dose; Quat. Sci. Rev. 25 2475-2502.

Chauhan N 2014 Luminescence dating: Basic approach to geochronology; Defect and Diffusion Forum 347 111-137.

Chauhan N, Choi J H, Kim J Y and Lee G 2015 Application of newly developed NCF-SAR protocol to Quaternary sediments from Suncheon and Jeongok, South Korea; Geosci. J. 19 407-413.

Chauhan N and Singhvi A K 2011 Distribution in SAR palaeodoses due to spatial heterogeniety of natural beta dose; Geochronometria 38190.

Galbraith R F 1990 Radial plots: Graphical assessment of spread in ages; Nucl. Tracks Radiat. Meas. 17 207-214.

Galbraith R F and Green P F 1990 Estimating the component ages in a finite mixture; Nucl. Tracks Radiat. Meas. 17 197-206.

Galbraith R F and Laslett G M 1993 Statistical models for mixed fission track ages; Nucl Tracks Radiat. Meas. 21 459-470.

Huntley D J 2006 An explanation of the Power-law decay of luminescence; J. Phys. Condens. Matter 18 1359-1365.

Huntley D J and Lamothe M 2001 Ubiquity of anomalous fading in K-feldspars and the measurement and correction for it in optical dating; Canadian J. Earth Sci. 38 10931106.

Jain M, Murray A S and Bøtter-Jensen L 2004 Optically stimulated luminescence dating: How significant is incomplete light exposure in fluvial environments?; Quaternaire 15 143-157.

Jain M and Singhvi A K 2001 Limits to depletion of bluegreen light stimulated luminescence in feldspars: Implications for quartz dating; Radiat. Meas. 33 883-892.

Juyal N, Raj R, Maurya D M, Chamyal L S and Singhvi A K 2000 Chronology of late Pleistocene environmental changes in the lower Mahi basin, western India; J. Quat. Sci. 15 501-508.

Kars R H, Wallinga J and Cohen K M 2008 A new approach towards anomalous fading correction for feldspar IRSL dating - tests on samples in field saturation; Radiat. Meas. 43 786-790.

Morthekai P, Jain M, Cunha P P, Azevedo J M and Singhvi A K 2011 An attempt to correct for the fading in million year old basaltic rocks; Geochronometria 38223 230.

Morthekai P, Singh R, Nag D, Chauhan N, Shukla A, Phartiyal B, Ali S N and Sharma A 2017 Sample size dependent OSL ages: Results from Ladakh, India; Int. Conf. Geology: Applications and Emerging Methods (GEM-2017), Abstract p. 29. 
Murray A S and Wintle A G 2000 Luminescence dating of quartz using an improved single-aliquot regenerative-dose protocol; Radiat. Meas. 32 57-73.

Olley J, Caitcheon G and Murray A 1998 The distribution of apparent dose as determined by optically stimulated luminescence in small aliquots of fluvial quartz: Implications for dating young sediments; Quat. Sci. Rev. 17 1033-1040.

Pant R k and Chamyal L S 1990 Quaternary sedimentation pattern and terrain evolution in the Mahi river, Gujarat, India; Proc. Indian Nat. Sci. Acad. 56 501511.

Pietsch T J, Olley J M and Nanson G C 2008 Fluvial transport as a natural luminescence sensitiser of quartz; Quat. Geochronol. 3 365-376.

Prescott J R and Hutton J T 1994 Cosmic ray contributions to dose rates for luminescence and ESR dating: Large depths and long-term time variations; Radiat. Meas. 23 497-500.

Reid I and Frostick L E 1997 Channelform, flow and sediments indeserts; In: Arid Zone Geomorphology; Wiley, Chichester.

Roberts R G, Galbraith R F, Yoshida H, Laslett G M and Olley J M 2000 Distinguishing dose populations in sediment mixtures: A test of single-grain optical dating procedures using mixtures of laboratory-dosed quartz; Radiat. Meas. 32 459-465.

Rodnight H, Duller G A T, Wintle A G and Tooth S 2006 Assessing the reproducibility and accuracy of optical dating of fluvial deposits; Quat. Geochronol. 1 109-120.

Singhvi A, Stokes S, Chauhan N, Nagar Y and Jaiswal M 2011 Changes in natural OSL sensitivity during single aliquot regeneration procedure and their implications for equivalent dose determination; Geochronometria 38 231-241.

Thomsen K J, Bøtter-Jensen L, Denby P M, Moska P and Murray A S 2006 Developments in luminescence measurement techniques; Radiat. Meas. 41 768-773.

Thomsen K J, Murray A S, Bøtter-Jensen L and Kinahan J 2007 Determination of burial dose in incompletely bleached fluvial samples using single grains of quartz; Radiat. Meas. 42 370-379.

Voinchet $\mathrm{P}$, Falguères $\mathrm{C}$, Tissoux $\mathrm{H}$, Bahain J J, Despriée $\mathrm{J}$ and Pirouelle F 2007 ESR dating of fluvial quartz: Estimate of the minimal distance transport required for getting a maximum optical bleaching; Quat. Geochronol. 2 $363-366$.

Zhao H and Li S H 2005 Internal dose rate to K-feldspar grains from radioactive elements other than potassium; Radiat. Meas. 40 84-93.

Corresponding editor: NAVIN JUYAL 